\title{
Ocena satysfakcji pacjentów użytkujących uzupełnienia ruchome w zależności od rodzaju protez i czasu ich użytkowania
}

\section{Evaluation of the satisfaction of patients using removable restorations depending on the type of the dentures and the time of their use}

\author{
Klinika Protetyki i Technologii Dentystycznych, Uniwersytet Medyczny im. Karola Marcinkowskiego w Poznaniu \\ Department of Prostheties and Dental Technology, Poznan University of Medical Sciences
}

DOI: http://dx.doi.org/10.20883/df.2020.12

\begin{abstract}
STRESZCZENIE
Wprowadzenie. Wydłużenie średniej długości życia powoduje, że liczba pacjentów wymagających rehabilitacji protetycznej z wykorzystaniem protez ruchomych wciąż wzrasta. Leczenie protetyczne ma na celu odbudowę utraconych zębów oraz przywrócenie ich funkcji, eliminowanie parafunkcji, zapobieganie schorzeniom podłoża protetycznego i zaburzeniom układu stomatognatycznego (US).

Z doniesień w piśmiennictwie wynika, że poprawnie wykonane protezy ruchome wpływają pozytywnie na poprawę jakości życia wśród badanych pacjentów i nie zależy ona od techniki wykonania protez.

Cel. Celem pracy była analiza jakości klinicznego i laboratoryjnego wykonania ruchomych uzupełnień protetycznych oraz ocena ich wpływu na akceptację protez i jakość życia pacjentów.

Materiał i metody. W badaniu uczestniczyło 56 osób. U każdego pacjenta wykonano badanie oceniające rodzaj braków dokonano oceny typu podłoża protetycznego (u pacjentów bezzębnych), ustalono czas użytkowania dotychczasowych protez, zakres, retencję i stabilizację oraz wysokość spoczynkową i zwarciową starych i nowych protez. Wykorzystano także ankietę oceny QoL. Wyniki poddano analizie statystycznej.

Wyniki. Z przeprowadzonych analiz wynika, że pacjenci nie przywiązują wagi do parametrów wyznaczanych na etapach rejestracji zwarcia. Największy wpływ na pozytywny odbiór protez mają retencja i stabilizacja uzupełnień. Wnioski. Na satysfakcję z użytkowania protez ruchomych ma wpływ właściwa retencja protezy szczęki.
\end{abstract}

Słowa kluczowe: satysfakcja z protez, wykonawstwo laboratoryjne, retencja, stabilizacja.

\section{ABSTRACT}

Introduction. The increase in life expectancy means that the number of patients requiring prosthetic rehabilitation using removable dentures is still increasing. Prosthetic treatment aims to rebuild lost teeth and restore these functions, eliminate parafunctions, prevent prosthetic conditions and disorders of the stomatognathic system (US). Reports from the literature say that correctly made removable dentures have a positive effect on improving the quality of life among the examined patients and it does not depend on the technique of making dentures.

Aim. The aim of the study was to analyze the quality of clinical and laboratory performance of removable dentures and to assess their impact on the acceptance of dentures and the quality of life of patients.

Material and Methods. 56 people participated in the study. Each patient underwent a test to assess the type of deficiencies, to assess the type of prosthetic base (for toothless patients), the time of use of existing prostheses, scope, retention and stabilization, as well as the resting and short-circuit height of old and new prostheses. A QoL assessment survey was also used. The results were statistically analyzed.

Results. The analyzes show that patients do not attach importance to the parameters determined at the stages of occlusion registration. Retention and stabilization of restorations have the greatest impact on the positive reception of dentures.

Conclusions. The proper retention of the jaw prosthesis has an impact on the satisfaction of using removable dentures.

Keywords: satisfaction with dentures, laboratory workmanship, retention, stabilization. 


\section{Wstęp}

Pomimo znacznego zainteresowania odbudowami protetycznymi na implantach, wydłużenie średniej długości życia powoduje, że liczba pacjentów wymagających rehabilitacji protetycznej z wykorzystaniem protez ruchomych wciąż wzrasta [1].

Powodem jest wysoki koszt leczenia implantoprotetycznego, zły stan ogólny zdrowia pacjentów w wieku podeszłym oraz niechęć do podejmowania dodatkowego ryzyka związanego z zabiegiem chirurgicznym. Ponadto niekorzystne warunki anatomiczne, takie jak znaczny zanik pionowy i poziomy kości oraz niewystarczająca ilość tkanek miękkich, uniemożliwiają $\mathrm{w}$ wielu przypadkach wykonanie zabiegu implantacji.

Z piśmiennictwa wynika, że liczba pacjentów wymagających rehabilitacji z wykorzystaniem protez całkowitych wynosi od $6 \%$ do $54,7 \%$ dorosłej populacji $[2,3]$. Według WHO bezzębie jest to forma upośledzenia fizycznego, ponieważ prowadzi do ograniczenia podstawowych funkcji życiowych i społecznych, takich jak artykulacja dźwięków mowy oraz żucie [4]. Leczenie protetyczne ma na celu odbudowę utraconych zębów oraz przywrócenie tych funkcji, eliminowanie parafunkcji, zapobieganie schorzeniom podłoża protetycznego i zaburzeniom układu stomatognatycznego (US). Poza poprawą estetyki, funkcji żucia i mowy przywraca również prawidłową wysokość zwarcia oraz umożliwia uzyskanie zadowalającej równowagi i stabilizacji US. Właściwie wykonane uzupełnienie protetyczne powinno stanowić główny element profilaktyki dysfunkcji skroniowo-żuchwowych (DSŻ) [5].

Odpowiednio wykonane protezy powinny posiadać anatomiczny kształt, przywracać dobrą wysokość zwarcia oraz relację żuchwy do szczęki, co umożliwia lepszą adaptację do protez oraz pozwala uzyskać korzystny efekt terapeutyczny. Ponadto warunkuje uzyskanie satysfakcji z wykonanych uzupełnień protetycznych. Nieprzestrzeganie podstawowych zasad w projektowaniu protez ruchomych lub brak wiedzy odnośnie poszczególnych etapów wykonawstwa uzupełnień protetycznych może wywoływać zaburzenia w obrębie US w postaci dysfunkcji skroniowo-żuchwowych [6].

Dane z piśmiennictwa wskazują, że u 50-70\% pacjentów występują mniej lub bardziej nasilone objawy patologii skroniowo-żuchwowych, w tym tylko $5-12 \%$ populacji to grupa pacjentów, u których stwierdzono DSŻ [7], z czego zaledwie 2-7\% poszukuje pomocy specjalistycznej. Problem ten dotyczy zarówno pacjentów uzębionych, jak i bezzębnych $[8,9]$.
Według danych z literatury wśród pacjentów bezzębnych częściej stwierdza się DSŻ, które mają cięższy przebieg, ze względu na większe ryzyko wystąpienia zapaleń kości i zmian destrukcyjnych w obrębie stawu skroniowo-żuchwowego [10]. Przeprowadzono wiele analiz badających wpływ protez ruchomych na jakość życia pacjentów (Quality of Life-QoL) bezzębnych [11-14]. Także w badaniach przeprowadzonych w Klinice Protetyki i Technologii Dentystycznych oceniano QoL pacjentów w momencie zgłoszenia się na leczenie oraz po wykonaniu nowych uzupełnień protetycznych [15].

$Z$ doniesień naukowych wynika, że poprawnie wykonane protezy ruchome wpływają pozytywnie na poprawę jakości życia wśród badanych pacjentów i nie zależy ona od techniki wykonania protez [16].

Celem pracy była ocena satysfakcji pacjentów $z$ użytkowanych uzupełnień ruchomych oraz analiza poprawności postępowania kliniczno-laboratoryjnego ustalanego $\mathrm{w}$ trakcie wykonywania uzupełnień protetycznych $w$ badanej grupie pacjentów, a także wykazanie, że pozytywny odbiór otrzymanych protez zależy od poprawności ich wykonania na etapie zarówno klinicznym jak i laboratoryjnym.

\section{Materiał i metody}

W badaniu uczestniczyło 56 osób w wieku 50-90 lat (średnia 68 lat), w tym 33 kobiety i 23 mężczyzn. Warunkiem zakwalifikowania do badania była konieczność użytkowania protez osiadających szczęki i żuchwy. Z badania wykluczono kobiety w ciąży, osoby z chorobami przewlekłymi i systemowymi, osoby po utracie wagi powyżej $10 \mathrm{~kg} \mathrm{w}$ okresie roku oraz pacjentów użytkujących protezy z elementami precyzyjnymi.

U każdego pacjenta wykonano badanie oceniające rodzaj braków wg klasyfikacji Kennedyego i Eichnera, dokonano oceny typu podłoża protetycznego wg Supple'a (u pacjentów bezzębnych), czas użytkowania dotychczasowych protez, zakres, retencję i stabilizację oraz wysokość spoczynkową i zwarciową starych i nowych protez. Na podstawie ankiety oceniano również akceptację i satysfakcję $z$ użytkowanych uzupełnień. Dodatkowo przeprowadzono badanie pod kątem występowania objawów bólowych, ruchowych i akustycznych DSŻ. Po wykonaniu nowych uzupełnień protetycznych każdy pacjent był badany oraz wypełniał ankietę. Wyniki poddano analizie statystycznej przy pomocy testu Fishera, który szacował istotność statystyczną pomiędzy badanymi cechami protez ru- 
chomych ocenianymi przez pacjentów. Ponadto przy użyciu testu Manna-Whitneya oceniano korelacje pomiędzy zakresem opuszczania żuchwy a zmianami zakresu bocznych dewiacji toru ruchu żuchwy podczas ruchu. Wyniki uznano za istotne statystycznie przy wartości p <0,05.

\section{Wyniki}

Do badań włączono pacjentów użytkujących: obie protezy całkowite (CD/CD), protezę całkowitą szczęki i protezę osiadającą częściową żuchwy (CD/RPD), protezę osiadającą częściową szczęki i protezę całkowitą żuchwy (RPD/CD) lub 2 protezy osiadające częściowe (RPD/RPD) (Wykres 1). Typ podłoża protetycznego wg Supple'a oraz klasyfikację braków zębowych wg Kennedy'ego i Eichnera w badanej grupie pacjentów przedstawia tabela 1.

Tabela 1. Typ podłoża protetycznego wg Supple'a oraz klasyfikacja braków zębowych wg Kennedy'ego i Eichnera w badanej grupie pacjentów

\begin{tabular}{|c|c|c|c|c|c|}
\hline $\begin{array}{c}\text { Typ } \\
\text { podłoża } \\
\text { wg } \\
\text { Supple'a } \\
\text { w szczęce/ } \\
\text { żuchwie }\end{array}$ & $\begin{array}{c}n \\
\text { pacjen- } \\
\text { tów }\end{array}$ & $\begin{array}{c}\text { Klasyfikacja } \\
\text { braków } \\
\text { zębowych } \\
\text { wg } \\
\text { Kennedy'ego } \\
\text { w szczęce/ } \\
\text { żuchwie }\end{array}$ & $\begin{array}{c}\mathrm{n} \\
\text { pa- } \\
\text { cjen- } \\
\text { tów }\end{array}$ & $\begin{array}{l}\text { Klasyfika- } \\
\text { cja } \\
\text { braków } \\
\text { zębowych } \\
\text { wg } \\
\text { Eichnera }\end{array}$ & $\begin{array}{c}n \\
\text { pacjen- } \\
\text { tów }\end{array}$ \\
\hline Idealne & $24 / 18$ & I & $5 / 10$ & C2 & 15 \\
\hline $\begin{array}{l}\text { Zanikłe } \\
\text { twarde }\end{array}$ & $11 / 21$ & II & $8 / 5$ & C3 & 16 \\
\hline $\begin{array}{l}\text { Zanikłe } \\
\text { miękkie }\end{array}$ & $12 / 13$ & III & $3 / 0$ & B1 & 5 \\
\hline \multirow[t]{3}{*}{ Rozwięzłe } & $9 / 4$ & IV & $2 / 4$ & B2 & 9 \\
\hline & & V & $0 / 0$ & B3 & 7 \\
\hline & & & & B4 & 4 \\
\hline
\end{tabular}

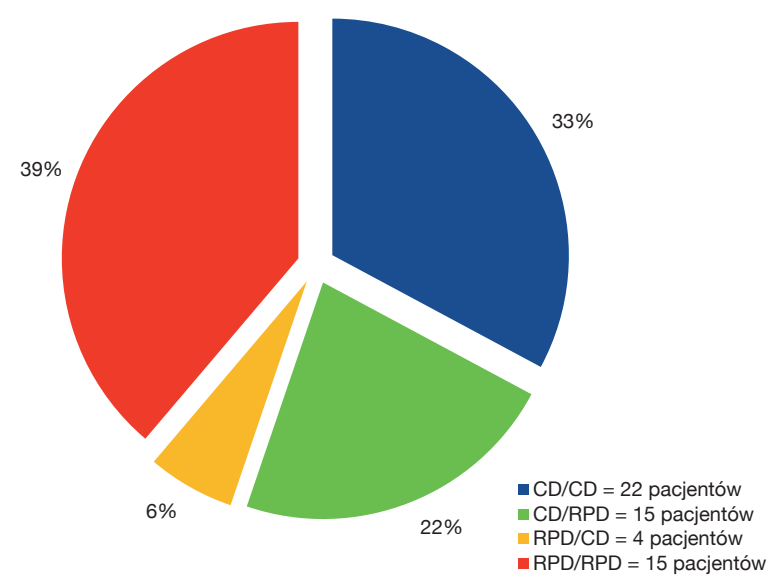

Wykres 1. Rozkład procentowy pacjentów użytkujących ruchome uzupełnienia protetyczne, $\mathrm{n}=56$
Okres użytkowania starych protez u osób, którzy byli z nich zadowoleni wynosił około 9 lat, natomiast u tych pacjentów, którzy nie byli usatysfakcjonowani z dotychczasowych uzupełnień - około 5 lat. Nie była to jednak różnica istotna statystycznie (dla szczęki $p=0,1544$; dla żuchwy $p=0,1857$ ) (Tabela 1).

Tabela 2. Porównanie satysfakcji pacjentów z użytkowanych uzupełnień protetycznych dla szczęki i żuchwy

\begin{tabular}{|c|c|c|c|c|}
\hline \multicolumn{2}{|c|}{$\begin{array}{c}\text { Akceptacja } \\
\text { starych } \\
\begin{array}{c}\text { protez } \\
\text { przez } \\
\text { pacjenta }\end{array}\end{array}$} & \multicolumn{2}{|c|}{ Szczęka } & \multicolumn{2}{c|}{ Żuchwa } \\
\cline { 2 - 6 } & liczba & $\%$ & liczba & $\%$ \\
\hline tak & 43 & 77 & 34 & 61 \\
\hline nie & 13 & 23 & 22 & 39 \\
\hline
\end{tabular}

Wyniki ocenianych parametrów wysokości spoczynkowej, zwarciowej, centralnej relacji oraz ogólnego stanu użytkowanych starych protez przedstawia tabela 3.

Po ocenie klinicznej pozostałych parametrów wyznaczanych w trakcie rejestracji zwarcia, tj. napięcia wargi górnej, płaszczyzny zwarcia, zasięgu płyty starych protez, oraz porównaniu ich z kwestionariuszem wypełnianym przez pacjenta Test Fishera wykazał brak zależności pomiędzy satysfakcją a napięciem wargi górnej starych protez $(p=0,544)$, płaszczyzną zwarcia $(p=0,4496)$, zasięgiem starej protezy całkowitej szczęki $(p=0,6363)$ oraz żuchwy ( $p=0,5232)$. Pacjenci nie przywiązywali wagi do parametrów wyznaczanych na etapach rejestracji zwarcia i nie wpływały one na akceptację użytkowanych protez.

Tabela 3. Parametry starych protez oceniane w trakcie badania

\begin{tabular}{|l|c|c|c|}
\hline \multirow{2}{*}{$\begin{array}{c}\text { Oceniane } \\
\text { parametry }\end{array}$} & & $\begin{array}{c}\mathrm{N}=56 \\
\text { badanych }\end{array}$ & $\%$ \\
\hline \multirow{2}{*}{$\begin{array}{l}\text { Wysokość } \\
\text { spoczynkowa }\end{array}$} & Prawidłowa & 25 & 45 \\
\cline { 2 - 4 } & Zawyżona & 0 & 0 \\
\hline \multirow{2}{*}{$\begin{array}{l}\text { Centralna } \\
\text { relacja }\end{array}$} & Prawidłona & 31 & 55 \\
\hline \multirow{2}{*}{$\begin{array}{l}\text { Napięcie } \\
\text { wargi }\end{array}$} & Nieprawidłowa & 32 & 43 \\
\cline { 2 - 4 } & Prawidłowe & 48 & 86 \\
\cline { 2 - 4 } & Nieprawidłowe & 8 & 14 \\
\hline $\begin{array}{l}\text { Płaszczyzna } \\
\text { zwarcia }\end{array}$ & Prawidłowa & 40 & 71 \\
\cline { 2 - 4 } & Nieprawidłowa & 16 & 29 \\
\hline
\end{tabular}


Wyraźny wpływ na pozytywny odbiór protez wykazano podczas analizy zależności między retencją a stabilizacją starej protezy całkowitej szczęki. W teście Fishera $p=0,0093$.

W przypadku protezy dolnej nie wykazano takiej zależności $(p=0,1132)$. Wyniki przedstawia tabela 4.

Tabela 4. Okres użytkowania starych protez a satysfakcja

\begin{tabular}{|c|c|c|c|c|c|}
\hline \multicolumn{6}{|c|}{ Okres użytkowania starych protez } \\
\hline \multicolumn{7}{|c|}{} & $\begin{array}{c}\text { N=56 } \\
\text { pacjen- } \\
\text { tów }\end{array}$ & $\begin{array}{c}\text { Śred- } \\
\text { nia }\end{array}$ & $\begin{array}{c}\text { Mini- } \\
\text { mum }\end{array}$ & $\begin{array}{c}\text { Maksi- } \\
\text { mum }\end{array}$ \\
\hline \multirow{4}{*}{ szczęka } & satysfakcja & 43 & 9 lat & 3 lata & 30 lat \\
\cline { 2 - 7 } & $\begin{array}{c}\text { brak } \\
\text { satysfakcji }\end{array}$ & 13 & 5 lat & $\begin{array}{c}1,5 \\
\text { roku }\end{array}$ & 8 lat \\
\hline \multirow{3}{*}{ żuchwa } & $\begin{array}{c}\text { satysfakcja } \\
\text { brak } \\
\text { satysfakcji }\end{array}$ & 22 & 9 lat & 3 lata & 30 lat \\
\hline
\end{tabular}

\section{Dyskusja}

Protezy ruchome pełnią funkcję leczniczą i profilaktyczną w stosunku do wszystkich elementów układu stomatognatycznego, jednak na skutek zaniku podłoża protetycznego, uszkodzeń użytkowanych uzupełnień oraz ich starzenia zachodzi konieczność ich systematycznej wymiany. Podczas kolejnych wizyt w trakcie wykonywania nowych uzupełnień protetycznych ustala się odpowiedni zakres, kształt oraz elementy estetyki istotne dla uzyskania zadowalającej satysfakcji pacjenta [1719]. Takie parametry jak wysokość i płaszczyzna zwarcia niewłaściwie ustalone mogą wpływać na wystąpienie objawów dysfunkcji US. Wyniki przeprowadzonych badań wskazują, że dla całkowitej satysfakcji pacjenta najistotniejsza jest retencja protezy szczęki. Zasięg protezy, płaszczyzna zwarcia lub właściwe podparcie wargi górnej nie miały w tym przypadkiu statystycznie istotnego wpływu na akceptację i satysfakcję z nowych uzupełnień. Co jest zgodne $z$ wynikami badań przeprowadzonych przez innych autorów [20].

Dobór grupy pacjentów, a także dobry stan zdrowia w ich własnej ocenie, jak również pytania zawarte $w$ ankiecie są porównywalne $z$ danymi prezentowanymi w innych publikacjach [21-23].

Dokładna analiza wskazuje, że najważniejszym czynnikiem wpływającym na wysoki stopień satysfakcji oraz poprawę jakości życia posiada stabilizacja oraz retencja użytkowanych uzupełnień protetycznych. Ma to szczególne znaczenie w przypadku protezy szczęki, gdzie wykazano wysoką istotność statystyczną ( $p=0,0093)$, przy czym nie miało to związku z satysfakcją użytkowanej protezy dolnej, gdzie $p=0,1132$. Zostało to potwierdzone przez innych autorów, którzy zauważyli, że na zwiększenie stopnia satysfakcji z użytkowanych protez ma wpływ zarówno wzrost retencji i stabilizacji protezy szczęki, jak i żuchwy [24]. Wykazali także, że istnieje pozytywna korelacja pomiędzy satysfakcją a stabilizacją protez. Z badań przeprowadzonych w innych ośrodkach wynika również, że to właśnie utrata tych parametrów jest najczęstszą przyczyną wykonania nowych uzupełnień [25].

Według naszych badań najczęstszym błędem popełnianym $\mathrm{w}$ trakcie wykonywania uzupełnień ruchomych, które w znaczny sposób zmniejszają satysfakcję pacjentów zarówno z użytkowanych protez, jak i jakości życia, jest wyznaczenie zbyt niskiej wysokości zgryzu. W badanej grupie parametr ten był nieprawidłowy aż u 55\% pacjentów. $Z$ piśmiennictwa wynika, że ten parametr jest nieprawidłowy wśród 70,3\% badanych [26-28].

Wbrew oczekiwaniom odpowiednie wyznaczenie centralnej relacji nie wpływa na komfort użytkowanych protez, a tym samym na zadowolenie pacjenta [29]. Nieprawidłowo wyznaczoną centralną relację stwierdzono w 57\%, a według innych źródeł w $36 \%$.

Z naszych obserwacji, a także obserwacji poczynionych przez innych autorów wynika, że pacjenci, którzy zgłaszają się w celu wykonania nowych protez, oceniają poziom swojej satysfakcji z życia znacznie niżej niż pacjenci uzębieni szukający rehabilitacji protetycznej [30-32]. Prawdopodobnie wynika to $z$ codziennych problemów, z którymi zmagają się pacjenci, takich jak zły wygląd, trudności z żuciem i mówieniem, obawa przed społecznym odrzuceniem. Poprawnie wykonane protezy ruchome wpływają na poprawę jakości życia, wydolność żucia, przywrócenie aktywności społecznej i poprawę jakości życia.

$Z$ zaprezentowanych przez nas badań, a także doniesień innych autorów wynika, że głównym parametrem wpływającym na pozytywna ocenę nowych protez przez pacjentów jest ich prawidłowa stabilizacja i retencja [33-35].

Zarówno w badaniach własnych, jak i innych autorów wykazano, że poprawność wykonania protez ma znaczący wpływ na jakość życia leczonych pacjentów [36-40]. Istotne jest, aby dokładnie rozpoznać problem, z jakim zgłasza się pacjent, postawić prawidłową diagnozę oraz wdrożyć odpowiednie postępowanie lecznicze. 


\section{Wnioski}

1. Największy wpływ na satysfakcję pacjenta z użytkowania protez ruchomych ma właściwa retencja protezy szczęki.

2. Zasięg protezy, płaszczyzna zwarcia, podparcie wargi górnej nie miały statystycznie istotnego wpływu na akceptację i satysfakcję z nowo wykonanych uzupełnień.

\section{Oświadczenia}

\section{Oświadczenie dotyczące konfliktu interesów}

Autorzy deklarują brak konfliktu interesów w autorstwie oraz publikacji pracy.

\section{Źródła finansowania}

Autorzy deklarują brak źródeł finansowania.

\section{Piśmiennictwo}

[1] Henry PJ. Tooth loss and implant replacement. Australian dental journal, 2000,45.3:150-172.

[2] Health Canada. Report on the Findings of the Oral Health Component of the Canadian Health Measures Survey 2007-2009. Ottawa, Ontario: Ministry of Health; 2010.

[3] Ribeiro MT, Rosa MA. Edentulism and shortened dental arch in Brazilian elderly from the National Survey of Oral Health 2003. Revista de Saúde Pública. 2011;45(5):817-823.

[4] Emami E, De Souza RF. The Impact of Edentulism on Oral and General Health. Int J Dent. 2013; 2013: 498305.

[5] Barrowman RA, Wilson PR. Oral rehabilitation with dental implants after cancer treatment. Just Dent J 2011; 56:160-165.

[6] Vojdani M, Bahrani F. The study of relationship between reported temporomandibular symptoms and clinical dysfunction index among university students in Shiraz. Dent Res J. 2012;9(2):221-225.

[7] Johansson A. Gender difference in symptoms related to temporomandibular disorders in a population of 50-year-old subjects. J Orofac Pain 2003; 17:29-35.

[8] Gonçalves DA, Camparis CM. Temporomandibular disorders are differentially associated with headache diagnoses: a controlled study. Clin J Pain. 2011;27(7):611-615

[9] Lim PF, Smith S. Development of temporomandibular disorders is associated with greater bodily pain experience. Clin J Pain. 2010;26(2):116-120.

[10] Gupta S, Gupta R, Garg R. Partial edentulism and Temporomandibular joint disorders. IOSR Journal of Dental and Medical Sciences. 2014;13(12):60-63.

[11] Yoshida M, Sato Y. Correlation between quality of life and denture satisfaction in elderly complete denture wearers. Int J Prosthodont. 2001;14(1):77-80.

[12] Koshino H, Hirai T. Quality of life and masticatory function in denture wearers. J Oral Rehabil. 2006;33(5):323-9.

[13] Szabó G, Kende D. Quality of life and prosthodontics. Fogorv Sz. 2006;99(3):91-8.
[14] John MT, Slade GD. Oral health-related quality of life in patients treated with fixed, removable, and complete dentures 1 month and 6 to 12 months after treatment. Int J Prosthodont. 2004;17(5):503-11.

[15] Yoshida M, Sato Y. Correlation between Quality of Life and Denture Satisfaction in Elderly Complete Denture Wearers. Int J Prosthodont. 2001;14(1): 77-80.

[16] Ellis JS, Elfeky AF. The impact of dietary advice on edentulous adults' denture satisfaction and oral health-related quality of life 6 months after intervention. Clin. Oral Impl. Res. 2010;21:386-391.

[17] Jensen PM, Saunders RL. Factors associated with oral health-related quality of life in communitydwelling elderly persons with disabilities. J Am Geriatr Soc. 2008;56(4):711-7.

[18] Locker D, Matear D. Oral health-related quality of life of a population of medically compromised elderly people. Community Dent Health. 2002 Jun;19(2):90-7.

[19] Gift HC, Redford M. Oral health and the quality of life. Clin Geriatr Med. 1992;8(3):673-83.

[20] Alfadda S, Al-Fallaj H. A clinical investigation of the relationship between the quality of conventional complete dentures and the patients' quality of life. The Saudi Dental Journal. 2015;27,:93-98.

[21] Awad MA. Mandibular and conventional dentures have the same impact on general satisfaction and oral health- related-quality of life. J Evid Based Dent Pract. 2007;7(2):69-70.

[22] Wolff A, Gadre A. Correlation between denture satisfaction with complete dentures and denture quality, oral condition and the flow rate of submandibular/sublingual glands. The International journal of prosthodontics 2003;16(1):45-8.

[23] Anastassiadou V, Naka O. Validation of indices for functional assessment of dentures. Gerodontology. 2002;19(1):46-52.

[24] Musavi S, Eslami H. Evaluation of Patients' Satisfaction with the Complete Denture made in Prosthodontics Department of Dentistry Faculty. ABCMED 6(2):9-13.

[25] Bilhan H, Erdogan O. Complication rates and patient satisfaction with removable dentures. J Adv Prosthodont 2012;4(2):109-115.

[26] Hadjieva H, Dimova M. Changes in the vertical dimension of occlusion during different periods of complete denture wear - a comparative study. Journal of IMAB - Annual Proceeding (Scientific Papers) $2014 ; 20$.

[27] Den Haan R, Witter DJ. Occlusal vertical dimension in removable complete dentures. Ned Tijdschr Tandheelkd. 2011;118(12):640-5.

[28] Sierpinska T, Golebiewska M. The influence of the occlusal vertical dimension on masticatory muscle activities and hyoid bone position in complete denture wearers. Adv Med Sci. 2009;54(1):104-118.

[29] Fish SF. Adaptation and habituation to full dentures. Br Dent J. 1969;127(1):19-26.

[30] Hoeksema AR, Peters LL. Health and quality of life differ between community living older people with and without remaining teeth who recently received 
formal home care: A cross sectional study. Clin Oral Invest. 2018;22(7):2615-2622.

[31] Albaker AM. The oral health-related quality of life in edentulous patients treated with conventional complete dentures. Gerodontology. 2013;30(1):61-6.

[32] Gjengedal H, Berg E. Self-reported oral health and denture satisfaction in partially and completely edentulous patients. Int J Prosthodont. 2011;24(1): 9-15.

[33] Alfadda S. The relationship between various parameters of complete denture quality and patients' satisfaction. J Dent Am Assoc. 2014;145(9):941-948.

[34] McCunniff M, Liu W. Patients' esthetic expectations and satisfaction with complete dentures. J Prosth Dent. 2017;118(2):159-165.

[35] Begum S, DamlaSener T. Satisfaction of the complete denture wearers related to various factors. Arch Geront Geriat. 2009;49(2):126-129.

[36] Zlatarić DK, Celebić A. The satisfaction with the removable partial denture therapy in the Croatian adult population. Coll Antropol. 2000;24(2):485-94.

[37] Celebić A, Knezović-Zlatarić D. Factors related to patient satisfaction with complete denture therapy. J Gerontol A Biol Sci Med Sci. 2003;58(10):M948-53.

[38] Celebić A, Knezović-Zlatarić D. A comparison of patient's satisfaction between complete and partial removable denture wearers. J Dent. 2003;31(7):445-51.
[39] Zlatarić DK, Celebić A. Treatment outcomes with removable partial dentures: a comparison between patient and prosthodontist assessments. Int J Prosthodont. 2001;14(5):423-6.

[40] Knezović Zlatarić D, Celebić A. A survey of treatment outcomes with removable partial dentures. J Oral Rehab. 2003;30(8):847-54.

Zaakceptowano do edycji: 2020-10-06 Zaakceptowano do publikacji: 2020-10-06

\section{Adres do korespondencji:}

Anna Sójka-Makowska

Katedra Protetyki Stomatologicznej i Klinika

Protetyki Uniwersytetu Medycznego

im. Karola Marcinkowskiego w Poznaniu

ul. Bukowska 70

60-812 Poznań

tel.: +48 505184842

fax: +48 618547094

e-mail:anna.sojka23@gmail.com 